\title{
A Prática da Atenção Primária à Saúde no Combate da Covid-19
}

Simone de Pinho Barbosa, Ana Valesca Fernandes Gilson Silva

\section{RESUMO}

O presente artigo avalia brevemente o papel central exercido pela Atenção Primária à Saúde no Combate da COVID-19 e aponta uma reflexão sobre as normativas dos atendimentos aos casos da COVID 19 e as condições das UBSs quanto a estrutura, profissionais, equipamentos e organização desses serviços.

Palavras-chave: COVID-19; Pandemia; Atenção Primária à Saúde.

Revista da Rede APS 2020

Publicada em: 15/04/2020

DOI:10.14295/ aps.v2i1.62

Simone de Pinho Barbosa

(Universidade Federal de Juiz de Fora, Governador Valadares;

\section{ABSTRACT}

This article briefly assesses the central role played by Primary Health Care in the Combat of COVID-19 and points out a reflection on the norms for attending cases of COVID 19 and the conditions of PHC units regarding the structure, professionals, equipment and organization of these services.

keywords: COVID-19; Pandemic; Primary Health Care.

Ana Valesca Fernandes

Gilson Silva

(SMS/Betim; Minas Gerais;

Brasil)

Correspondência para:

Simone de Pinho Barbosa

sidepinho@gmail.com 
A Pandemia do Novo Corona vírus assim decretada pela Organização Mundial de Saúde (OMS) e classificada como Emergência de Saúde Pública II, a de mais alto nível de gravidade, tem desafiado nações e estadistas a tomarem medidas em tempo oportuno para o controle do número de casos, impondo aos sistemas de saúde um desempenho frenético, sobretudo de ajustamentos às necessidade urgentes para o combate desse surto.

No Brasil, a disseminação tem crescido segundo os Boletins do Ministério da Saúde definindo a necessidade imediata de capilarização das informações e ações para as comunidades, medidas essas de controle dos casos de Síndrome Respiratória Aguda Grave (SRAG) ${ }^{1}$. Este cenário pandêmico aponta que, além dos hospitais e Unidades de Pronto Atendimento, as UBSs e suas equipes de profissionais respondem ao primeiro contato do paciente com o serviço de saúde, sendo fundamental para a contenção da disseminação do vírus.

A APS desempenha um papel decisivo na proteção da saúde, na prevenção e controle de doenças infecciosas através do diagnóstico precoce, tratamento, acompanhamento e monitoramento individual e familiar, sendo fundamental ao processo saúde/doença. 0 controle de infecções incluem medidas que reduzem o risco de transmissão na própria unidade, no domicílio e na comunidade.

As medidas de controle para prevenção de transmissão de patógenos são determinadas internacionalmente e definem as ações considerando o modo de transmissão de cada tipo de doença. Nos serviços de saúde a prevenção e controle ocorrem em dois níveis de precaução: o padrão e o específico ${ }^{2}$. O processo de trabalho na APS envolve medidas de precauções como a higienização das mãos, o uso de equipamentos de proteção individual, métodos de limpeza e desinfecção de instrumentos e superfícies e a manipulação e acondicionamento adequado dos resíduos de saúde. Entretanto diversos estudos apontam que os profissionais da APS, não possuem ou possuem pouco conhecimento específico sobre as precauções. O conhecimento sobre as precauções é fundamental, porém diversos outros fatores como a falta de estrutura e capacitação, a garantia dos materiais, os conflitos de papéis e competências profissionais, podem afetar essas práticas. Entretanto o volume de pacientes, as complexidades culturais, institucionais e as políticas de saúde influenciam nas medidas de precauções ${ }^{3,4}$.

Aponta-se aqui uma reflexão sobre as normativas dos atendimentos aos casos da COVID 19 e as condições das UBSs quanto a estrutura, profissionais, equipamentos e organização desses serviços. O novo coronavírus implicou na exigência de medidas efetivas de controle de infecção com consequente encaminhamento diário de protocolos, fluxogramas, fast tracks e notas técnicas para orientar as ações dos serviços. Habituados à assistência em epidemias como Dengue e Zika, os profissionais de saúde da APS se deparam com rotinas externas às suas práticas assistenciais. Prover áreas de isolamento em estruturas físicas precárias, paramentar e desparamentar os EPIs, utilizar parâmetros como saturação de oxigênio e temperatura aferida através de oxímetro e termômetro infravermelho, instrumentos estes inexistentes em UBSs, manter o distanciamento necessário e garantir os atendimentos de gestantes, crianças, vacinação e medicação devem ser pensados pelas autoridades para que ocorram de forma segura e efetiva.

É preciso de forma rápida e lúcida se debruçar sobre os desafios postos à APS no que tange às demandas da COVID19, garantindo investimentos e capacitação necessárias, reconhecendo a singularidade do trabalho executado por essas equipes e o tipo de densidade tecnológica que as mesmas operam, e quais recursos têm sido garantidos a esses serviços e profissionais para que atuem de forma técnica, científica, digna e humanitária. 


\section{NOTAS E REFERÊNCIAS}

${ }^{1}$ MINISTERIO DA SAÚDE. Secretaria de Vigilância em Saúde. Centro de Operações em Emergências em Saúde Pública. Boletim Epidemiológico 06. Brasília, 2020.

${ }^{2}$ Sako MP, Felix AMS, Kawagoe JY, Padoveze MC, Ferreira SA, Zem-Mascarenhas SH, et al. Knowledge about precautions in Primary Health Care: tool validation. Rev Bras Enferm [Internet]. 2018;71(Suppl 4):1589-95. [Thematic Issue: Education and teaching in Nursing] DOI: http://dx.doi.org/10.1590/00347167-2017-0886

${ }^{3}$ Ali Alfahan, Samia Alhabib, Imad Abdulmajeed, Saeed Rahman \& Samira Bamuhair (2016) In the era of corona virus: health care professionals' knowledge, attitudes, and practice of hand hygiene in Saudi primary care centers: a cross-sectional study, Journal of Community Hospital Internal Medicine Perspectives, 6:4, DOI: 10.3402/jchimp.v6.32151

${ }^{4}$ Maroldi, M.A.C., Felix, A.M., Dias, A.A.L. et al. Adherence to precautions for preventing the transmission of microorganisms in primary health care: a qualitative study. BMC Nurs 16, 49 (2017). https://doi.org/10.1186/s12912-017-0245-z 